\title{
Weight Reduction in an AA2017 Aluminum Alloy Part through the Gas Forming Process of a Blank with a Variable Thickness
}

\author{
Gillo Giuliano, Wilma Polini \\ Department of Civil and Mechanical Engineering, University of Cassino and Southern Lazio, via G. di Biasio 43, \\ 03043 Cassino. Italy. E-mail: giuliano@unicas.it, polini@unicas.it
}

Lighter and lighter products are required by aerospace and automotive sectors in order to reduce fuel cost and carbon dioxide emissions and, to allow using green energy propulsion, such as the electric one. In order to lighten parts aluminium alloys, which have a high strength to weight ratio, are the most commonly used metal materials. They are manufactured through plastic deformation processes often by using tailored blanks. This work focuses the attention on semi-finished products obtained by subtracting material through machining; they are a further class of tailored blanks.

In this work, the design of a simple (almost hemispherical) aluminium alloy sheet component in AA2017 aluminium alloy is analysed, with the help of finite element analysis. In order to reduce the component weight; a circular blank was used, characterised by a variable initial profile of the thickness instead of the conventional disc with a constant initial thickness. Given that a more uniform final thickness profile is determined, enhanced resistance characteristics of the product component are achieved. Therefore, the workpiece will be characterized by a weight reduction of about $8 \%$ compared to the analogous obtained from a blank with a constant initial thickness.

Keywords: gas forming process, free-forming test, formability, AA2017 aluminum alloy, finite element method

\section{Introduction}

The new trends of design are oriented towards lighter and lighter products, involving lighter and lighter parts. These lighter parts are very flexible and may adapt their shape by elastic deformation during assembling and, therefore, they are called "compliant parts" [1]. Examples of lightweight materials are thin sheet metal or polymer matrix composite, which are becoming more common in many sectors, such as aerospace and automotive ones. In these sectors, the use of lightweight materials in the so-called "lightweight design" leads to reduced fuel cost and carbon dioxide emissions, and it allows to use of green energy propulsions, such as the electric one: all these are relevant topics in international research projects. This is the motivation why compliant assemblies are moving from the niche of special product manufacturing to batch or even mass production.

In order to lighten parts aluminium alloys, which have a high strength to weight ratio, are the most commonly used metal materials. They are manufactured through plastic deformation processes for both aerospace and automotive applications [2]. Moreover, the use of tailored blanks for plastic deformation processes also substantially contributes to this objective [3]. Tailored blanks are blanks optimized to locally modify some properties of the sheet metal (thickness, material, etc.). Tailored blanks can be obtained by wel- ding processes [4-5], using custom-rolled semi-finished products [6-8] or heat treated locally [9-10]. To prevent the welding process from causing distortion of the sheet and to partially reinforce the sheet itself, it is possible to add patches where required, using an adhesive bonding operation [11-13] before executing the forming process.

Different resistance properties of the produced component can be achieved by using multi-phase processes [14-19] or through processing that subtracts material from a blank characterized by a constant initial thickness. The multi-phase processes were used both for a superplastic material [14-16] and for a common light alloy [17-19]. Since they require higher production costs, in this work, the focus was on semifinished products obtained by subtracting material through machining. These semi-finished products constitute a further class of tailored blanks.

Due to the reduced formability of aluminium alloys [20], the blanks obtained by chip removal processes have been hot deformed by a hot gas forming process at a temperature greater than $0.5 \mathrm{~T}_{\mathrm{f}}$ (with $\mathrm{T}_{\mathrm{f}}$ the material melting temperature in $\mathrm{K}$ ). This process is schematically similar to the superplastic forming process [21-23] (Figure 1a) and, unlike the latter, it uses a higher forming speed [23-26] and non-superplastic materials. The higher forming speed justifies the name of the process (i.e. quick plastic forming) introduced by General Motors and successfully applied to the automotive industry [23-24]. 
In a hot forming process of the metal sheet the material is highly sensitive to the strain rate. Residual stresses and cracks may arise after heat treatment of forgings from heat-treatable aluminium alloys [27]. In [28-29], it was found that in a hot gas forming process, starting from a sheet with a constant initial thickness, the produced thinning is the result of different local stresses inside the material during the forming process. Therefore, to form a hemispherical component, a gradient of the stresses between the pole and the outer edge of the dome is produced which induces a gradient of the thicknesses. The reached thickness profile depends on the strain rate sensitivity index, $\mathrm{m}$. It has been shown that for superplastic materials, which are characterized by a value of $m>0.3$, the tendency to develop thickness gradients is low. For non-superplastic materials, characterized by a value of $\mathrm{m}$ much lower than the superplastic materials, greater gradients of thickness are produced.

In [30-32], simple superplastic forming processes were analysed from a blank characterised by a variable initial thickness profile. These works are strongly focused on defining the initial thickness profile of the semi-finished product through the use of optimisation techniques. No consideration is developed on the possibility to improve the formability of the material by conditioning the state of deformation of the produced component. In addition, they proposed discontinuous initial thickness profiles and do not provide guidance on how to prepare the semi-finished workpiece in practice.

In this work, the design of a simple component with spherical geometry in AA 2017 aluminium alloy is analyzed starting from a circular blank characterized by an initial profile of the variable thicknesses and obtained through a gas forming process. In this way, it was possible to obtain a lighter component with a more uniform final thickness profile. The gas sheet metal forming process could be a solution to reduce the weight of the parts for the automotive or aerospace industry and in general for transports.

\section{Gas sheet metal forming}

The process of gas sheet metal forming was carried out using the self-designed equipment that was presented in [33]. This equipment required, in the first processing phase, the blank to be heated to a temperature of $405{ }^{\circ} \mathrm{C}$. Once the process temperature was reached, the air was introduced into the die at constant pressure $(\mathrm{p}=0.8 \mathrm{MPa})$. During the process, a control system allows maintaining constant the temperature of the metal sheet while, through a measuring laser, it is possible to record the height at the peak of the dome as a function of the processing time.

The material used to conduct the experimental activity is the aluminium alloy AA2017. The chemical composition by weight of the material is as follows: $\mathrm{Al}-4.5 \% \mathrm{Cu}-1 \% \mathrm{Mn}-1 \% \mathrm{Mg}-0.8 \% \mathrm{Si}-0.7 \% \mathrm{Fe}$. The material has a high cold mechanical strength and is generally used for various structural applications. It was acquired in the form of a sheet with an initial thickness of $1 \mathrm{~mm}$. The initial thickness of some semi-finished sheets was machined, by removing chips, to obtain a blank whose thickness profile is linearly variable as shown in Fig. 1b. In [34], the mechanical properties of the material were derived through the blow forming test and presented. The hardening law of the material is characterized by the power-law:

$$
\bar{\sigma}=C \bar{\varepsilon}^{n} \dot{\bar{\varepsilon}}^{m}
$$

where $\bar{\sigma}$ is the equivalent stress, $\dot{\bar{\varepsilon}}$ is the strain rate, $\bar{\varepsilon}$ is the equivalent strain, $\mathrm{m}$ is the strain rate sensitivity index, and $\mathrm{C}$ is the strength coefficient.

Then, the AA2017 alloy was submitted to a hot gas sheet metal forming process at constant pressure $(\mathrm{p}=0.8 \mathrm{MPa})$ using two geometrically different initial blanks: i) a circular sheet with a diameter of $80 \mathrm{~mm}$ and a thickness of $1 \mathrm{~mm}$ and ii) a circular sheet with a diameter of $80 \mathrm{~mm}$ and a thickness profile as that shown in Fig. 1b.

At the end of the forming process, the thickness of the deformed sheet was measured with the help of a Prismo Vast MPS coordinate measuring machine of Zeiss ${ }^{\circledR}$. Two sets of points belonging to the internal and external surfaces of the deformed sheet were measured to which a geometric algorithm was applied in order to achieve the thickness trend of the measured sheet. Fig. 2 shows some steps in the measurement process.

\section{Finite element analysis}

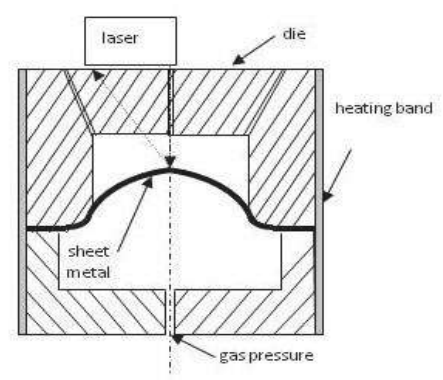

(a)

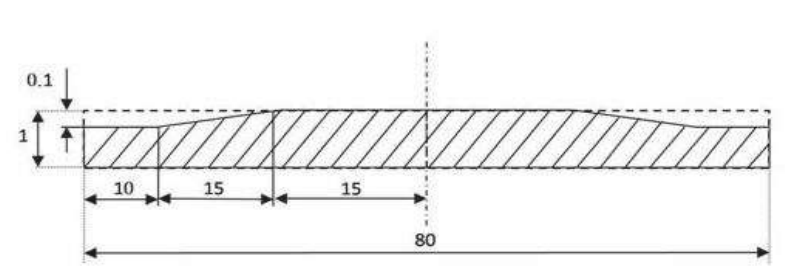

(b)

Fig. 1 a)Hot gas sheet metal forming process scheme and b)initial variable thicknesses profile of a sheet 


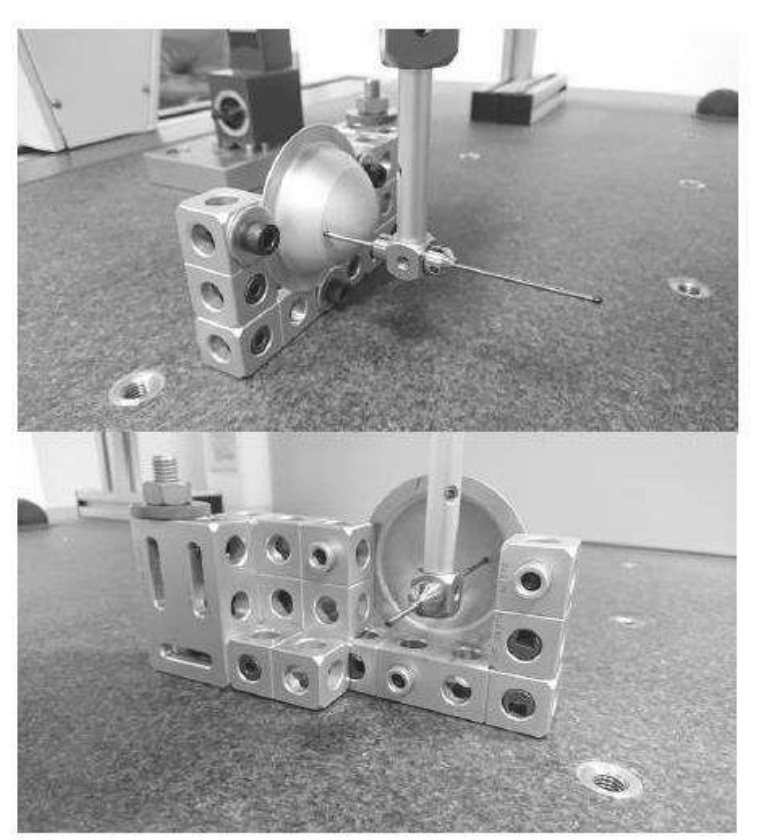

Fig. 2 Steps of the thickness measurement process

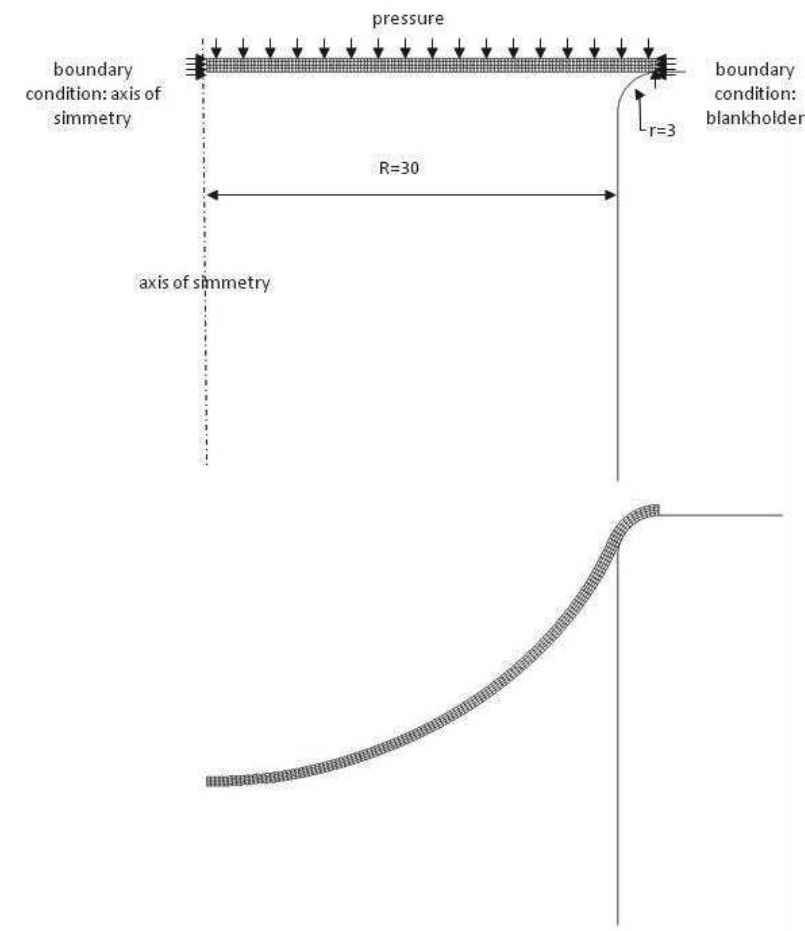

Fig. 3 FEM simulation of gas sheet metal forming process

Finite element analysis was developed to assist the design of the spherical component to be obtained through a gas forming process starting from a circular blank characterized by an initial profile of the variable thicknesses. Preliminary, a series of numerical simulations based on finite element analysis was carried out to identify as the strain rate sensitivity index, $\mathrm{m}$, influences the thickness trend of a spherical component. In these simulations, the parameter $m$ was varied from 0.2 to 0.7 . The FEM analysis was conducted using 528 axial symmetric elements at 4-nodes arranged over four layers that make up the deformable sheet. The nodes arranged on the symmetry axis are bound not to move in a direction orthogonal to the symmetry axis. The action of the blank holder, which has the task of preventing the sheet metal from slipping inside the die during the forming process, was simulated by blocking the nodes' displacement where the blank holder acts. A uniform and constant pressure were applied on one side of the metal sheet. Fig. 3, concerning the case $\mathrm{m}=0.5$, highlights the geometric aspects of the faced problem as well as the shape assumed by the deformed sheet at a height at the dome top of $20 \mathrm{~mm}$.

\section{Results and discussion}

The results of the preliminary numerical simulations, introduced in the previous paragraph, are shown in Fig. 4. The figure represents the trend of the obtained thicknesses in the produced component. Fig. 4 shows that, as the parameter $\mathrm{m}$ increases, the thickness trend tends to become uniform.

Moreover, in this work, it is possible to compare the FEM results with those from an approximate analytical analysis presented in [35]. This analysis provides that the trend of the thicknesses varies along the arc length, 1 , according to a relationship observed experimentally in [36] and of the type:

$$
s(l)=s_{p}+\left(s_{e}-s_{p}\right)\left(\frac{l}{L}\right)^{2}
$$

where $\mathrm{L}$ represents the current arc length of the deformed sheet and the indices $e$ and $p$ refer, respectively, to the edge and the pole of the dome. Therefore, once the relationship $s_{e}=f\left(s_{p}\right)$ is known, the thicknesses trend may be drawn.

In [33], the relationship between the thickness at the edge thickness and that at the pole is:

$$
s_{e}=\left[(1-K) s_{0}^{1 / m}+K s_{p}^{1 / m}\right]^{m}
$$

where $\mathrm{K}=\left(\frac{\sqrt{3}}{2}\right)^{\frac{1+\mathrm{m}}{\mathrm{m}}}$ and $\mathrm{s}_{0}$ is the initial thickness of the sheet.

For superplastic materials, for which $m>0.3$, the thickness trend, obtained from FEM, is compared with that obtained by the approximate analysis, i.e. that of eq. (2), in Fig. 5. Fig. 5 shows that, although the thickness distribution obtained from FEM is parabolic, the difference between the thickness due to the approximate analysis of eq. (2) and that from FEM grows by moving towards the plate edge. The maximum error is about $9 \%$. This error is due to the simplified hypothesis of the analytical model that does not consider a sliding of the sheet material on the flange 
and on the connection radius of the die. The material sliding, therefore, proceeds from the edge to the pole. This error increases for non-superplastic materials that are for $m<0.3$. In this case, the maximum error reaches $11 \%$ (see Fig. 6).

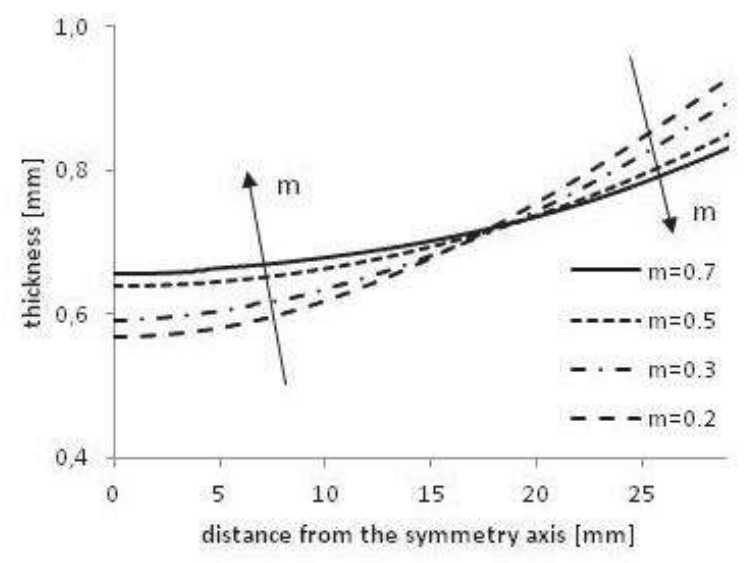

Fig. 4 Influence of the parameter $m$ on the thickness trend in a gas sheet metal forming process on a sheet with a constant initial thickness $(20 \mathrm{~mm})$
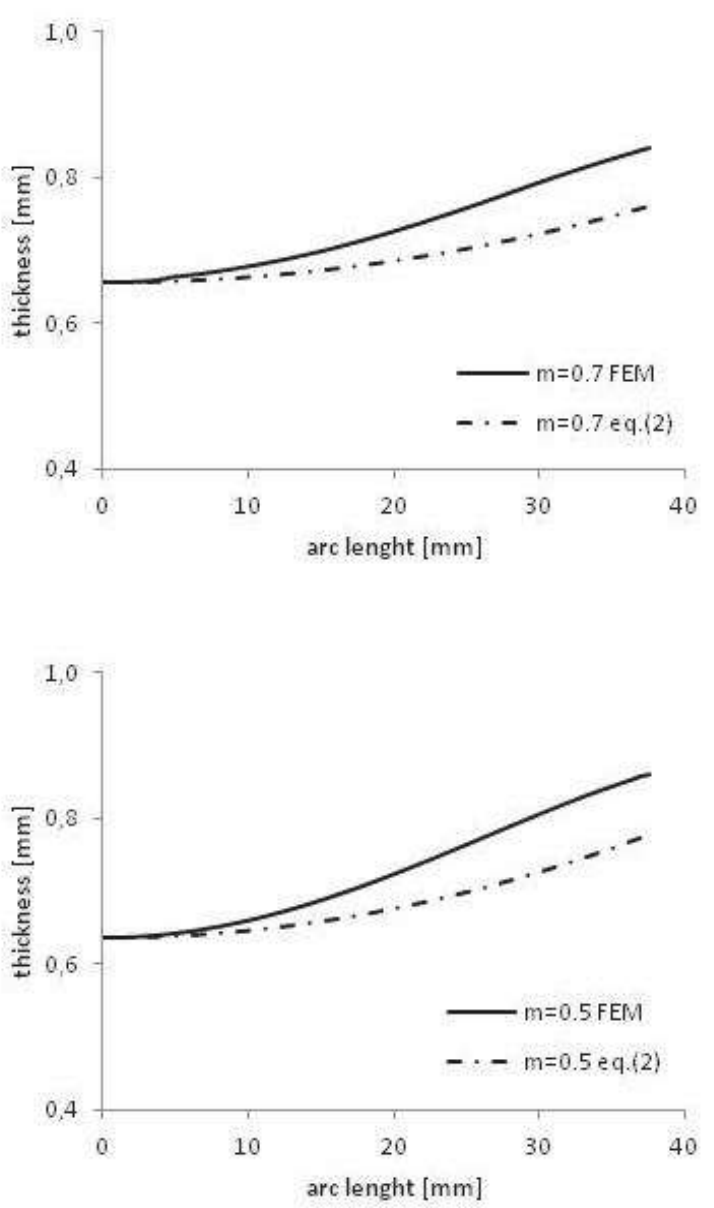

Fig. 5 Superplastic materials ( $m>0.3$ ): comparison between the trend of FEM and that due to the analytical model of eq.

(2)
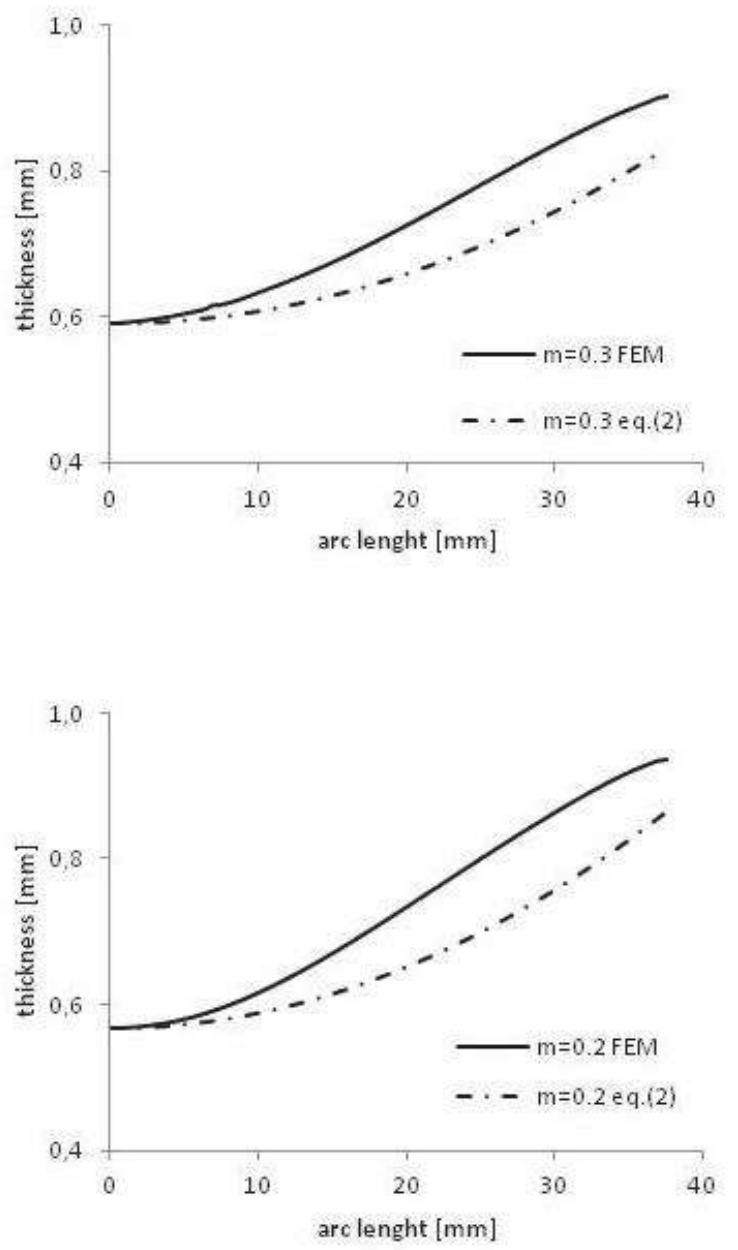

Fig. 6 Non superplastic materials $(m<0.3)$ : comparison between the trend of FEM and that due to the analytical model of eq. (2)

In the present work, using the finite element method, the ratio between the sheet thickness at the edge and that at the pole $s_{e} / s_{p}$ was evaluated once the values of the initial sheet thickness were fixed $\left(\mathrm{s}_{0 \mathrm{p}}=1\right.$ $\mathrm{mm}$ and $\mathrm{s}_{0 \mathrm{e}}=0.9 \mathrm{~mm}$ ) as shown in Fig. 1b. Fig. 7 shows that the thicknesses trend, once fixed the final forming height $(\mathrm{h}=20 \mathrm{~mm})$, is more uniform than the sheet metal forming process carried out from a blank with a constant initial thickness (initial thickness $=1$ $\mathrm{mm})$. A parameter that measures the uniformity of the thickness distribution can be defined as:

$$
\mathbf{U}=\left(\frac{\mathrm{s}_{\mathrm{e}}-\mathbf{s}_{\mathrm{p}}}{\mathrm{s}_{\mathrm{p}}}\right) \cdot \mathbf{1 0 0}
$$

The $\mathrm{U}$ value decreases from $28 \%$ to $2 \%$ for $\mathrm{m}=$ 0.3 and from $33 \%$ to $1 \%$ for $m=0.2$. Consequently, once observed that, by suitably profiling the initial thickness of the blank, it is possible to make uniform the thicknesses of the manufactured product, an experimental activity was conducted to validate the numerical model. 
Using AA2017 aluminium sheets, two hot sheet metal forming processes were carried out at constant pressure $(\mathrm{p}=0.8 \mathrm{MPa})$ :

one using sheets with the constant initial thickness $(\mathrm{s}=1 \mathrm{~mm})$,

another using sheets with the variable initial thickness (the initial profile of the thicknesses is shown in Fig. 1b).

The sheet with a variable initial thickness is characterized by a weight reduced of about $8 \%$ compared to the weight of the sheet with a constant initial thickness. Each test condition was replicated 3 times.

By using a workpiece with a variable initial thickness, the breakage occurred after having reached a height at the apex of the dome equal to $29.9 \mathrm{~mm}$ (Fig. 8a). This value is higher than that obtained using sheets with the constant initial thickness $(27.6 \mathrm{~mm})$. In this way, an increase in height at the dome apex of about $8 \%$ was produced which implies an improvement in the formability of the material.
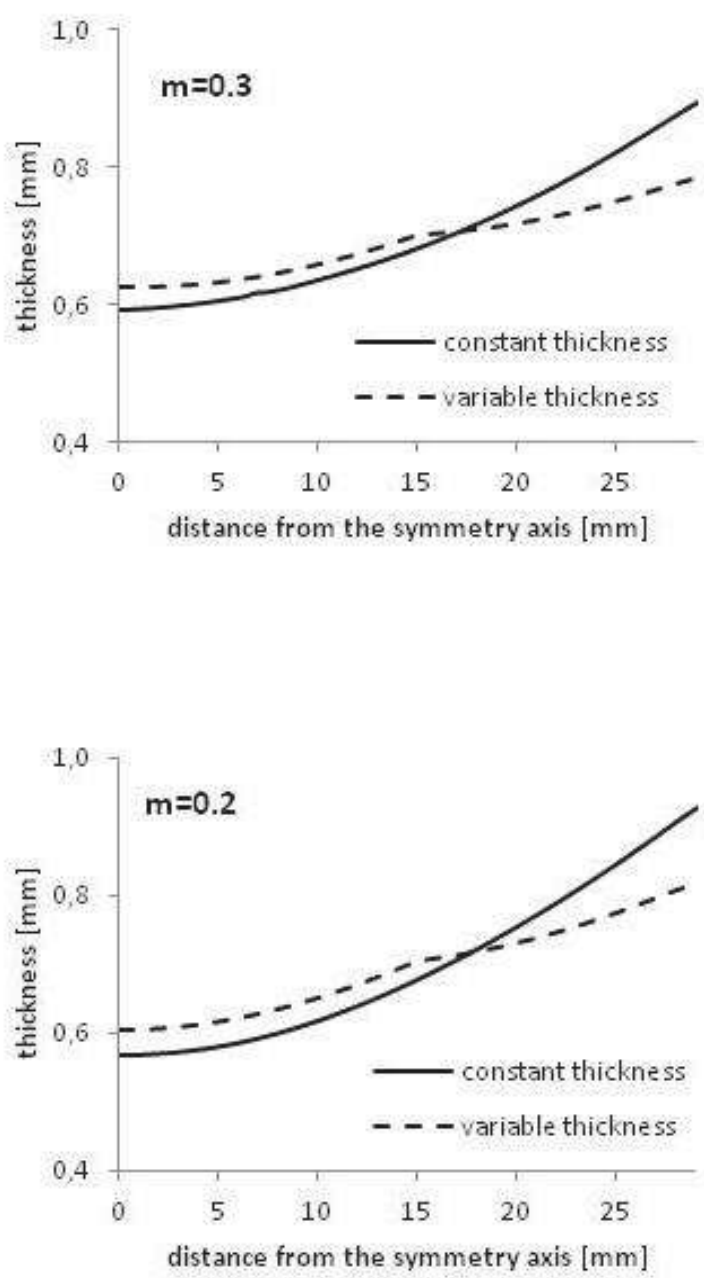

Fig. 7 FEM comparison in terms of thicknesses trend resulting from a gas sheet metal forming process between a sheet with an initial constant thickness and a sheet with a thickness variable as represented in Fig, $1 \mathrm{~b}$
The validation of the numerical model was obtained by measuring the thicknesses trend of the formed components until reaching a predetermined height of $27 \mathrm{~mm}$.

Fig. 8b shows the comparison between the experimental and numerical results in terms of the thickness distribution. From the figure, it is possible to note that:

the thicknesses trend is more uniform by adopting a sheet characterized by a variable initial thickness. The U value, measured by FEM, decreased from 129 $\%$ to $85 \%$ from a constant initial thickness process to a variable initial thickness process.

The trend of FEM thicknesses is in good agreement with the experimental results. The maximum percentage of variation found is about $10 \%$.

The U-value, measured experimentally, is reduced from $173 \%$ to $122 \%$.

\section{Conclusions}

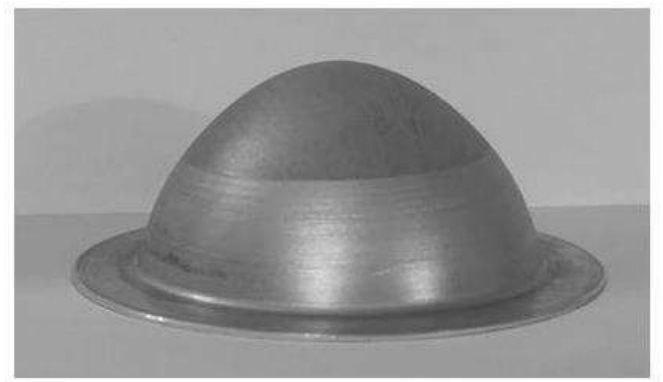

(a)

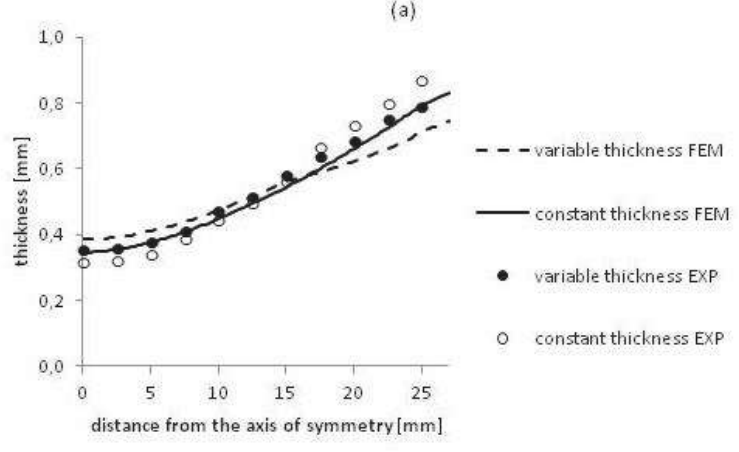

(b)

Fig. $\boldsymbol{8}$ (a)Deformed sheet with variable initial thickness, (b)Numerical-experimental comparison between the thicknesses trend resulting from a gas sheet metal forming process, with a constant and a variable initial thickness of the metal sheet

To reduce the weight of parts in aluminium alloy, this work analyzed, through FEM, the design of a spherical component in AA2017 aluminium alloy subjected to the hot sheet metal forming process. The aim was achieved by changing the initial profile of the sheet thicknesses compared to the conventional process that requires a sheet with a constant initial thickness. Weight was reduced by approximately $8 \%$. 
Furthermore, the process, carried out with variable initial thickness sheets, allows increasing the material formability of about $8 \%$. Moreover, it allows to uniform the final distribution of the thicknesses by enhancing the resistance performances of the product component. It has been found, by FEM, that the percentage ratio between the thickness measured at the edge and the pole of the sheet and the thickness at the pole decreases passing from a process with a constant initial thickness to a process with a variable initial thickness.

\section{Acknowledgement}

This research did not receive any specific grant from funding agencies in the public, commercial or not-for-profit sectors.

\section{References}

[1] POLINI, W., CORRADO, A. (2019). Uncertainty in manufacturing of lightweight products in composite laminate-part 2: experimental validation. In: International Journal of Advanced Manufacturing Technology, Vol. 101, pp. 1391-1401.

[2] SOLFRONK, P, SOBOTKA, J, KORECEK, D. (2020). Utilization of Advanced Computational Methods to Predict Spring-back of Alumium Alloys in Automotive Industry. In: $\mathrm{Ma}$ nufacturing Technology, Vol. 20, No. 1, pp. 98-103.

[3] JO, D.S., KIM, J.H., KIM, B.M. (2019). Feasibility study on application of hot forming quenching to patchwork blanks using two-stage refilled friction stir spot welding. In: Journal of $\mathrm{Ma}$ nufacturing Processes, Vol. 41, pp. 66-73.

[4] ZADPOOR, A.A., SINKE, J., BENEDICTUS, R. (2007). Mechanics of tailor welded blanks: an overview. In: Key Engineering Materials, Vol. 344, pp. 373-382.

[5] KINSEY, B.L., WU, X. (2011). Tailor welded blanks for advanced manufacturing. Woodhead $\mathrm{Pu}-$ blishing Limited.

[6] KOPP, R., WIEDNER, C., MEYER, A. (2005). Flexibly rolled sheet metal and its use in sheet metal forming. In: Advanced Materials Research, Vol. 6-8, pp. 81-92.

[7] KLINKE, N., SCHUMACHER, A. (2016). Finding the best thickness run parameterization for optimization of Tailor Rolled Blanks. In: LS-DYNA Forum 2016. Bamberg, Germany.

[8] HAN, S., HWANG, T., OH, I., CHOI, M., MOON, Y. H. (2018). Manufacturing of tailorrolled blanks with thickness variations in both the longitudinal and latitudinal directions. In:
Journal of Materials Processing Technology, Vol. 256, pp. 172-182.

[9] GEIGER, M., MERKLEIN, M. (2007). Sheet metal forming - a new kind of forge for the future. In: Key Engineering Materials, Vol. 344, pp. 9-20.

[10] KAHRIMANIDIS, A., LECHNER, M., DEGNER, J., WORTBERG, D., MERKLEIN, M. (2015). Process design of aluminum tailor heat treated blanks. In: Materials, Vol. 8, pp. 8524-8538.

[11] STREITBERGER, H.-J., DOSSEL, K.-F. (2008). Automotive Paints and Coatings. Wiley$\mathrm{VCH}$, Weinheim.

[12] PETITJEAN, P.-D., LESCART, J.-C., SENER, J.-Y., DELFANNE, S. (2001). Patchworks: from design o manufacture. In: Revue de Métallurgie, Vol. 98, pp. 911-926.

[13] GIULIANO, G., PARODO, G., SORRENTINO, L. (2020). Uniformity of thickness of metal sheets by patchwork blanks: potential of adhesive bonding. In: Frattura ed Integrità Strutturale, Vol. 53, pp. 166-176.

[14] AKKUS, N., SUZUKI, K., KAWAHARA, M., NISHIMURA, H. (1999). Influence of performing on the final thickness distribution of the superplastically deformed domes. In: Materials Science Forum, Vol. 304-306, pp.759-764.

[15] LUCKEY, G., FRIEDMAN, P., WEINMANN, K. (2009). Design and experimental validation of a two-stage superplastic forming die. In: Journal of Materials Processing Technology, Vol. 209, pp. 2152-60.

[16] GIULIANO, G., CORRADO, A., POLINI, W. (2018). Influence of multiphase forming approach on the thickness uniformity of components from superplastic PbSn60 alloy. In: Manufacturing Letters, Vol. 18, pp. 16-19.

[17] GIULIANO, G. (2018). Gas blow forming multiphase process using a non-superplastic material. In: Journal of Manufacturing Technology Research, Vol. 10, No. 1-2, pp. 82-88.

[18] GIULIANO, G. (2019). Multiphase gas blow forming of AA2017. In: Journal of Testing and Evaluation, Vol. 47, No. 2, pp. 1236-1243.

[19] GIULIANO, G, CORRADO, A, POLINI, W. (2019). On the gas blow forming multiphase process of an AA5083 aluminium alloy sheet. In: Journal of Manufacturing Technology Research, Vol. 11, No. 1-2, pp. 1-11. 
[20] SOBOTKA, J, SOLFRONK, P, KORECEK, D. (2020). Influence of Stress Strain on Yield Strength of Aluminium Alloy. In: Manufacturing Technology, Vol. 20, No. 1, pp. 92-97.

[21] PILLING, J, RIDLEY, N. (1989). Superplasticity in Crystalline Solids. Institute of Metals.

[22] AKSENOV, S.A., CHUMACHENKO, E.N., KOLESNIKOV, A. V., OSIPOV, S.A. (2015). Determination of optimal gas forming conditions from free bulging tests at constant pressure. In: Journal of Materials Processing Technology, Vol. 217, pp. 158-164.

[23] GIULIANO, G. (2011). Superplastic Forming of Advanced Metallic Materials: Methods and Applications. Cambridge, UK: Woodhead Publishing Ltd.

[24] BOISSIERE, R., TERZI, S., BLANDIN, J.J., SALVO, L. (2008). Quick-plastic forming: similarities and differences with super-plastic forming. In: 6th EUROSPF Conference, Carcassonne, France, 3-5 September.

[25] GIULIANO, G., SAMANI, F. (2016). Comparison between superplastic and non-superplastic grade AA 5083. In: Journal of Testing and Evaluation, Vol. 44, No. 6, pp. 2114-2119.

[26] GIULIANO, G. (2017). Gas blow forming in AA2017 aluminium alloy. In: Materials Science Forum, Vol. 878, pp. 13-17.

[27] LUŠTINEC, J, OČENÁŠEK, V. (2019). Residual Stresses and Cracks in Forgings of Heattreatable Aluminium Alloys. In: Manufacturing Technology, Vol. 19, No. 4, pp. 637-643.

[28] HAMILTON, C.H., GHOSH, A.K. (1988). Superplastic sheet forming. In: S.L. Semiatin (Ed.), Metals Handbook ASM, Metals Park, pp. 852-873.
[29] GIULIANO, G., POLINI, W. (2020). Influence of blank variable thickness on the material formability in hot gas sheet metal forming process. In: Manufacturing Letters, Vol. 24, pp.72-76.

[30] KIM, Y.H., LEE, J.M., HONG, S.S. (2001). Optimal design of superplastic forming processes. In: Journal of Material Processing Technology, Vol. 112, No. 2-3, pp. 166-173.

[31] HUANG, A., LOWE, A., CARDEW-HILL, M.J. (2001). Experimental validation of sheet thickness optimization for superplastic forming of engineering structures. In: Journal of Material Processing Technology, Vol. 112, No. 1, pp. 136143.

[32] DUTTA, A. (2004). Thickness-profiling of initial blank for superplastic forming of uniformly thick domes. In: Material Science and Engineering $A$, Vol. 371, No. 1-2, pp. 79-81.

[33] GIOVINCO, G., GIULIANO, G., TESTA, G. (2010). Forming apparatus to investigate the effect of temperature on the superplastic behaviour of alloys. In: AIP Conference Proceedings, Vol. 1252, pp. 304-11.

[34] GIULIANO, G. (2016). On the constitutive equation of AA2017 aluminium alloy at high temperature. In: Manufacturing Letters, Vol. 10, pp. 10-3.

[35] CHENG, J.H. (1994). A procedure for designing initial thickness variation for superplastic free inflation. In: International Journal of Mechanical Sciences, Vol. 36, pp. 981-1000.

[36] GHOSH, A.K., HAMILTON, C.H. (1982). Influences of material parameters and microstructure on superplastic forming. In: $\mathrm{Me}$ tallurgical Transactions A, Vol. 13, pp. 733-743. 